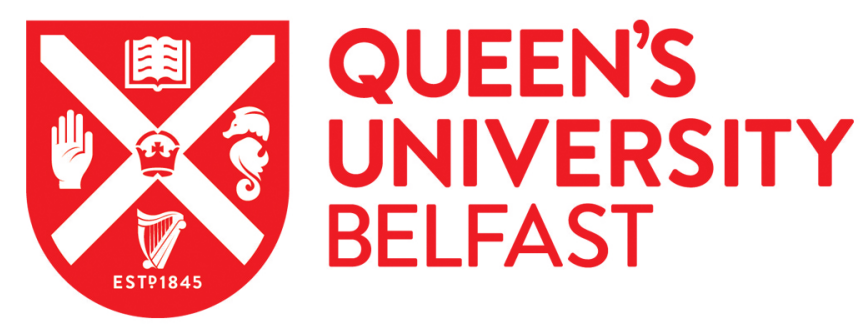

\title{
A unified scale for female reproductive stages in the Norway lobster (Nephrops norvegicus): Evidence from macroscopic and microscopic characterization
}

Becker, C., Cunningham, E. M., Dick, J. T. A., Eagling, L. E., \& Sigwart, J. D. (2018). A unified scale for female reproductive stages in the Norway lobster (Nephrops norvegicus): Evidence from macroscopic and microscopic characterization. Journal of morphology, 279(12), 1700-1715. https://doi.org/10.1002/jmor.20852

Published in:

Journal of morphology

Document Version:

Peer reviewed version

Queen's University Belfast - Research Portal:

Link to publication record in Queen's University Belfast Research Portal

Publisher rights

Copyright 2018 Wiley. This work is made available online in accordance with the publisher's policies. Please refer to any applicable terms of use of the publisher.

\section{General rights}

Copyright for the publications made accessible via the Queen's University Belfast Research Portal is retained by the author(s) and / or other copyright owners and it is a condition of accessing these publications that users recognise and abide by the legal requirements associated with these rights.

\section{Take down policy}

The Research Portal is Queen's institutional repository that provides access to Queen's research output. Every effort has been made to ensure that content in the Research Portal does not infringe any person's rights, or applicable UK laws. If you discover content in the

Research Portal that you believe breaches copyright or violates any law, please contact openaccess@qub.ac.uk. 


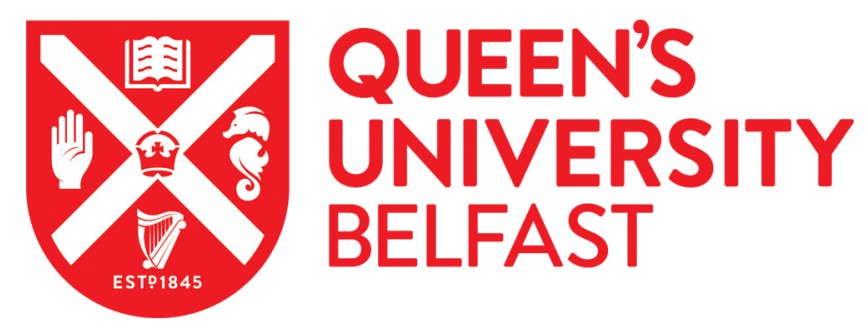

\section{A unified scale for female reproductive stages in the Norway lobster (Nephrops norvegicus): Evidence from macroscopic and microscopic characterization}

Becker, C., Cunningham, E. M., Dick, J. T. A., Eagling, L. E., \& Sigwart, J. D. (2018). A unified scale for female reproductive stages in the Norway lobster (Nephrops norvegicus): Evidence from macroscopic and microscopic characterization. Journal of morphology, 279(12), 1700-1715. https://doi.org/10.1002/jmor.20852

Published in:

Journal of morphology

Document Version:

Peer reviewed version

Queen's University Belfast - Research Portal:

Link to publication record in Queen's University Belfast Research Portal

Publisher rights

Copyright 2018 Wiley. This work is made available online in accordance with the publisher's policies. Please refer to any applicable terms of use of the publisher.

\section{General rights}

Copyright for the publications made accessible via the Queen's University Belfast Research Portal is retained by the author(s) and / or other copyright owners and it is a condition of accessing these publications that users recognise and abide by the legal requirements associated with these rights.

\section{Take down policy}

The Research Portal is Queen's institutional repository that provides access to Queen's research output. Every effort has been made to ensure that content in the Research Portal does not infringe any person's rights, or applicable UK laws. If you discover content in the

Research Portal that you believe breaches copyright or violates any law, please contact openaccess@qub.ac.uk. 


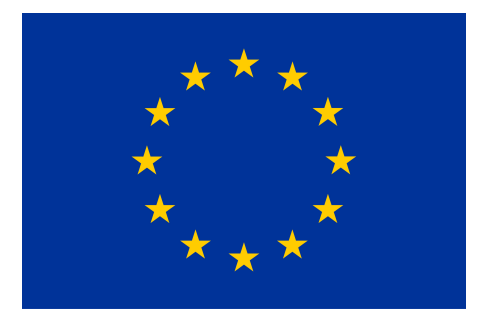

This project has received funding from the European Union's Horizon 2020 research and innovation programme under the Marie Skłodowska-Curie grant agreement No H2020-MSCAIF-2014-655661.

This copy of the accepted manuscript is provided to enable dissemination through Open Access to the scientific data; the version of record is that provided by the publishers. 


\title{
A complete illustrated version of this manuscript is available from the publisher or by request from the authors
}

https://onlinelibrary.wiley.com/doi/full/10.1002/jmor.20852

\section{A unified scale for female reproductive stages in the Norway lobster (Nephrops norvegicus): Evidence from macroscopic and microscopic characterization}

Carola Becker ${ }^{1}$, E. Mánus Cunningham ${ }^{1}$, Jaimie T.A. Dick ${ }^{1,2}$, Lawrence Eagling ${ }^{1}$, Julia D. Sigwart $^{1}$

${ }^{1}$ Queen's University Marine Laboratory, 12-13 The Strand, Portaferry BT22 1PF, United Kingdom

${ }^{2}$ Institute for Global Food Security, School of Biological Sciences, Queen's University Belfast, MBC, 97 Lisburn Road, Belfast BT9 7BL, Northern Ireland, UK

\begin{abstract}
Knowledge of the reproductive cycle in exploited species is important for a sustainable management of fisheries. Standardized scales to assess maturity stages are a fundamental tool to understand the demographic composition of exploited populations. Staging scales for female Norway lobster, Nephrops norvegicus, have been subject to a series of changes, and multiple inconsistent scales are in use in different fisheries regions. A unified, evidence-based scale has not previously been established. We reviewed previous staging scales for the female ovary maturation and propose a revised scale based on the correlation between macroscopic and microscopic ovary characteristics. To provide better-informed tools for future stock assessment, female stages were characterized through external observation on ovary color and size, and the progress of vitellogenesis. This study clarifies several biological phases that were conflated in previous scales. First, we demonstrate how to distinguish between immature ovaries in juvenile females versus the earliest ovary maturation stage in adults. Second, the new scale differentiates between "mottled" ovaries seen in two separate biological stages: the spent ovaries that undergo partial resorption in berried females, versus ovaries of females which failed to spawn and undergo full resorption. To ensure consistent application, colors are assessed relative to
\end{abstract}


international standards (RAL/Pantone). This new, practical staging scheme clarifies the correlation between microscopic characteristics and macroscopically observable details in ovary maturation. Adoption of this unified staging scale will improve maturity analyses, help to identify stocks with potentially reduced reproductive capacity, and facilitate broad-scale comparisons.

\section{INTRODUCTION}

The Norway lobster, Nephrops norvegicus (Linnaeus, 1758), is one of the most economically valuable fisheries resources in Europe and by far the most important exploited crustacean species in U.K. waters. In 2010, more than half of the total 66,500 t caught in Europe were landed in the U.K., with a large proportion being exported to other European countries (Ungfors et al., 2013). The total market value of all U.K. landings was more than 100 million pounds sterling in 2016 (Seafish, 2018).

Studies on reproductive cycles provide important information for the sustainable management of exploited species by identifying the seasonality of key life history events such as mating and spawning (e.g., Powell \& Eriksson, 2013). Estimates of the points when males and females first reach sexual maturity [size at onset of sexual maturity (SOM)] are the basis for implementing minimal landing sizes (MLSs) in fisheries. Only consistent, standardized collection of data allows comparisons across fisheries and different functional units (FUs) among stocks.

\subsection{The female reproductive cycle and ovary maturation}

In U.K. and Irish waters, mating in $N$. norvegicus occurs in spring immediately after the female moults (Farmer, 1974; Smith, 1987). Spermatozoa received during copulation are stored in the female sperm storage organ until ovulation, fertilization, and egg-laying (spawning) occurs in late summer to autumn (de Figueiredo \& Thomas, 1967; Farmer, 1974; Symonds, 1972; Thomas, 1964). Extruded eggs are attached to pleopods where embryos are incubated for 8-10 months over winter until larvae hatch in spring (Powell \& Eriksson, 2013). Females molt afterward and the cycle is resumed. In the Irish Sea, N. norvegicus have an annual reproductive cycle (Farmer, 1974) while for other geographic regions, including some areas of the North Sea, biennial reproductive cycles have been discussed (e.g., Eiríksson, 1993; Symonds, 1972). 
The development of ovaries in N. norvegicus is characterized by an increase in ovary size and a transition in color. The gonadosomatic index (GSI) is a calculation of the proportion of the gonad in relation to the total body mass (see Tuck, Taylor, Atkinson, Gramitto, \& Smith, 1997). As the GSI is laborious to assess under field conditions, where a rapid evaluation of stages in large sample batches is required, thus estimates from external observations have more utility. In field conditions, measurements of size (body length) and the overall color and texture of the ovary can by assessed rapidly, but for macroscopic characteristics to be useful, they must be grounded in clear biological stages. Ovary maturation is reflected in changes in the biochemical composition

of the ovary associated with the yolk formation (Rosa \& Nunes, 2002; Tuck et al., 1997). The accumulation of yolk (vitellogenesis) in ova (oocytes) provides nutrients, which are stored to later support the developing embryo. The progression of vitellogenesis becomes macroscopically evident by a transition in ovary color from light through different darkening shades of green during maturation. These are the stages that can be observed through rapid dissection of specimens. On the microscopic or histological level, ovary maturation (oogenesis) is characterized by the proliferation of oocytes and their stage in vitellogenesis.

Studies on the oogenesis of $N$. norvegicus have mostly been conducted in the period of $1960 \mathrm{~s}$ and 1970s (see Rotllant, Ribes, Company, \& Durfort, 2005). In that period, a reproducible incorporation of microscopic observations into staging scales had been hampered due to the rather low quality of printed histological figures (de Figueiredo, 1972; de Figueiredo \& Barraca, 1963; Farmer, 1974). Now, accurate color reproduction in print, as well as the rapidly increasing use of data tablets and smartphones in the field, enables the practical use of full color staging guides.

\subsection{Staging scales}

Ovary maturation of $N$. norvegicus has been the subject of numerous studies to establish staging scales (Supporting Information Table S1). These can be used to rapidly assess the demographic composition of large catches, for example, on board of trawl vessels. Macroscopic observations (Bailey, 1984; Briggs, 1988; Thomas, 1964) and microscopic studies (de Figueiredo, 1972; Farmer, 1974; Rotllant et al., 2005) have likewise been used in these scales (Supporting Information Table S1). However, very few studies have incorporated both approaches (see 
Farmer, 1974), and there are discrepancies among the staging scales used in different fisheries regions.

One of the first staging scales was proposed by Thomas (1964) and later adapted by other researchers (e.g., Bailey, 1984; Farmer, 1974; Symonds, 1972). The various scales used in recent decades during $N$. norvegicus stock surveys differ in the number and delimitation of stages. For example, Smith (1987) identified nine ovary maturation stages, while most other studies only recognize five to six (Supporting Information Table S1). There is also a considerable variation in how colors are described in the literature. Hardly any study provides color images (see Powell \& Eriksson, 2013), while most rely on text descriptions. The only staging scales that uses a standardized nomenclature for colors (based on Ridgway, 1912) is the scale by Thomas (1964). Farmer (1974) was the first to validate each macroscopic stage with microscopic observations. His scale is based on de Figueiredo and Barraca (1963) and Thomas (1964) but additionally recognizes a stage for resorbing ovaries. Different regional fisheries agencies have used versions of these many scales, leading to potential inconsistencies in what a given stage-number means from region to region.

\subsection{Ovary resorption}

Ovary resorption, also termed oosorption or reabsorption, is a phenomenon observed in several species of lobsters (Homarus americanus: Aiken \& Waddy, 1980; Talbot \& Helluy, 1995; Homarus gammarus: MacDiarmid \& Sainte-Marie, 2006), including N. norvegicus (de Figueiredo, 1982). Ovaries undergoing resorption look "mottled" (Farmer, 1974) as they are characterized by a speckled bicolored appearance (green with light spots or vice versa). Resorbing ovaries were either overlooked or were not represented in data that were used to develop early scales (de Figueiredo \& Barraca, 1963; Thomas, 1964). Symonds (1972) and Farmer (1974) were the first to assign mottled ovaries to a separate stage. Farmer (1974) interpreted them as spent ovaries (in recently spawned females) representing a few remaining oocytes that undergo resorption. Later, de Figueiredo (1982) demonstrated that ovary resorption in N. norvegicus is not only restricted to spent ovaries in berried (ovigerous) females but can also occur in females that skip a reproductive cycle. The causes for resorbing ovaries instead of spawning remain unknown (Tuck et al., 1997). The only staging scales that differentiate between 
a partial resorption in spent ovaries on the one hand, and a full resorption in females that fail to reproduce on the other hand, are by de Figueiredo (1982) and Bailey (1984). While some standard scales include a single "mottled" stage (Supporting Information Table S1), these two fates are clearly different, and that has implications for estimating the reproductive output of a population.

\subsection{Problems and aims}

Inconsistencies in staging scales obviously pose a problem for the standardization and comparability of collected data. The International Council of the Exploration of the Sea (ICES) has addressed this issue in expert group meetings aiming to establish a standardized scale for surveys conducted by partner institutions across Europe (ICES, 2004; ICES, 2009). Despite this effort, a comprehensive, universally used standard scale has not prevailed, and different staging scales are still in use. We suggest that the various staging scales used by different agencies have practical strengths and weaknesses, and what is needed to prompt adoption of a new scale is a significant improvement in practical utility and biological accuracy.

The first goal of this study was to review previously published (and applied) staging scales to test whether these scales meet the actually observed biological phases in female $N$. norvegicus. Inconsistencies and issues in such scales were documented to provide a cross-calibration or translation for data recorded under different scales. The second goal was to study ovary maturation in $N$. norvegicuson a macroscopic and microscopic level with special emphasis on ovary resorption. For macroscopic staging, we used a standardized color palette (RAL) to allow for an exact and reproducible assessment of observed colors. Histological sections were prepared for a large number of specimens to provide a detailed description of oogenesis in $N$. norvegicus to test whether defined microscopic characteristics in ovaries of different stages are reflected by diagnostic macroscopic features. The process of resorption has been studied in detail in this study for the first time.

By reviewing the available information on staging scales and incorporating our histological findings into external observations from this study, we present a revised staging scale for female $N$. norvegicus. Furthermore, we provide color images of all stages, which can be used as a scale on surveys. Based on the recorded color codes, we additionally developed a color chart, 
which can be adopted as a staging tool as well. The results of the herein presented study will allow cross-comparison of staging in different fisheries regions and a more robust understanding of $N$. norvegicus demographic structure.

\section{MATERIAL AND METHODS}

\subsection{Material}

The samples of N. norvegicus (Linnaeus, 1758) used in this study were collected at different sites in the Irish Sea (including Strangford Lough) and in the Farn Deeps of the North Sea. In total, 426 specimens were staged macroscopically, a subsample of 36 specimens was used for microscopic analyses (Supporting Information Tables S2 and S3). A batch of 15 female specimens from Strangford Lough was procured through a local fisherman on May 25, 2016 deploying creels from a boat centrally in the Lough (Tip Reef, $54^{\circ} 27^{\prime} 55 \mathrm{~N} 05^{\circ} 34^{\prime} 80 \mathrm{~W}$ ) at depths from 10 to $25 \mathrm{~m}$ (Supporting Information Table S2). Another batch of 59 female specimens was collected during a trawl survey conducted by the Agri-Food and Biosciences Institute of Northern Ireland (AFBI) in the western Irish Sea from August 9, 2016 to August 13, 2016 (Supporting Information Table S2). Additional samples from creel catches from the Northumberland coast in the Farn Deeps were provided by Kilkeel Seafoods in 2017. A total of 163 females was staged in February (February 1, 2017) and 189 females in March (March 14, 2017). As samples from Strangford Lough and from the Farn Deeps were procured through fisheries and thus above the minimum landing sizes, juvenile females were not present.

\subsection{Macroscopic analysis and dissection}

During AFBI trawl surveys, a standard protocol for trawl surveys was used to divide females initially according to a six stage scale onboard (Supporting Information Table S1). Macroscopic observations on Strangford Lough and Farn Deeps samples were made at Queen's University Marine Laboratory (Portaferry, Northern Ireland, U.K.).

Specimens were opened between the posterior carapace margin and the pleon (tail) to lay open the posterior ovarian lobes. In total, 426 specimens were staged according to an estimation of color and ovary size. In females which are close to reaching sexual maturity (around $20 \mathrm{~mm}$ carapace length in the Irish Sea) and starting their first reproductive cycle, immature ovaries 
were visible macroscopically, however in small juvenile females, ovaries were not conspicuous and females were preserved as whole specimens for microscopic observations. Subsamples of female specimens were taken from each of the six stages for a more detailed macroscopic and microscopic analysis of ovaries. Female carapace lengths (CLs) were measure from the posterior orbital margin to the posterior carapace margin using an electronic caliper. Females were dissected by removing the dorsal carapace and photographed together with a RAL chart containing the matching color (see 2.3). The recorded stages were later converted into the new staging scale presented in this study. For samples from the Farn Deeps, the same procedure was applied in the laboratory but specimens were immediately staged according to the new staging scale. In all samples, ovaries of ovigerous females were staged as well but recorded separately from females without eggs.

\subsection{Color assessment}

Specimens used in this study were photographed and staged using a RAL color chart (RAL K7 classic). RAL is the most commonly used standardized color matching system in Europe. The color chart fans used for staging contain 213 different colors (RAL gGmbH; Sankt Augustin, Germany), each represented by a four digits number, which allows exact reproducibility of colors and conversions into other color systems. The code of the RAL color that matched (or was closest to) the observed color was noted together with the specimen ID (Supporting Information Table S2). As the RAL color chart did not provide enough colors for the exact description of green shades observed in the ovaries of $N$. norvegicus(especially for Stage 2), some subsequent changes were necessary to reproduce the correct colors for the provided staging charts. Based on the photographs of specimens together with color charts and notes taken during color assessments, approximate RAL color codes were changed into better matching Pantone colors. Pantone color matching system (Pantone Inc., Carlstadt, New Jersey) provides charts with more than 1,800 different shades, which allows a much more accurate assessment, but is less practicable in the field. Adaptations from RAL to other standard color descriptions were done using online conversion tools (http://www.pantone.com/color-finder; http://rgb.to/), which provide Pantone, RGB or CMYK values for each color. Those values were used to reproduce colors in Adobe Photoshop (ver. CS5.1) and assemble the staging color charts. 


\subsection{Microscopic analysis}

In total, 36 specimens were used for histology (Supporting Information Table S3). Tissue samples for microscopic observations were taken from the posterior ovarian lobes and preserved in Bouin's solution or in "Susa Heidenhain" (MORPHISTO ${ }^{\circledR}$ Evolutionsforschung und Anwendung GmbH, Frankfurt am Main, Germany) for 1-2 weeks. Susa-fixed samples were then washed in a descending series of ethanol $(100 \%, 96 \%, 90 \%, 80 \%, 70 \%)$; Bouin-fixed samples were repeatedly washed in $70 \%$ ethanol. Samples were subsequently stored in $70 \%$ ethanol before their use in following procedures. In small specimens where we sectioned the whole anterior body (thorax), samples were treated with ethylenediaminetetraacetic acid (EDTA) for 48-72 hr for decalcification. Specimens were then dehydrated through an ascending series of ethanol solutions and infiltrated (Shandon Hypercenter XP; Thermo Fisher Scientific, Waltham, MA) and embedded for longitudinal sections through ovarian lobes in paraffin blocks. Sections were prepared at 6-8 $\mu \mathrm{m}$ using a Leica RM2255 rotary microtome (Leica Microsystems GmbH; Wetzlar, Germany). Longitudinal sections were always produced beyond the point where germinative zones appeared in full dimension to obtain sections from a central region of the ovary with a good representation of both, germinative and maturation zones, to allow for accurate comparison. All histological sections were stained using a trichromatic Masson-Goldner

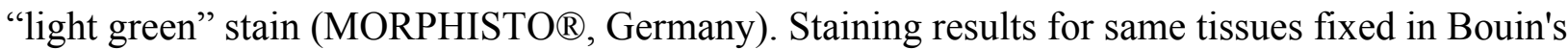
solution and Susa Heidenhain respectively were consistent. Covered slides were studied and photographed using an Olympus BX41 compound microscope equipped with an Olympus E600 camera. Images were processed and assembled to figure plates in Adobe Photoshop (ver. CS5.1).

All aspects of this research complied with protocols approved by the appropriate institutional animal care committee and adhered to the legal requirements in the U.K.

\section{RESULTS}

\subsection{Overview}

Based on macroscopic and microscopic observations, we discriminate between eight different stages of maturation in the ovaries of $N$. norvegicus (Figures 1-5; Table 1). For practicality, and to be as consistent as possible with earlier staging scales, we maintain a numbering system from 
0 to 5 with additional stages indicated by the letters a-b. In the following, we provide detailed descriptions and a guide to identifying the relevant stages.

\subsection{Macroscopic observations}

The ovary is formed by two parallel strands, one on each side of thorax (Figures 2and 3). The left and right strands are connected by a central commissure. The ovary, therefore, appears X- or Hshaped with two anterior and posterior lobes separated by the commissure. The ovary is predominantly located in the female thorax but can extend into the first pleomers with the progression of maturation (Figure 2; Stage 3 and 4).

Here, we differentiate between immature ovaries of juvenile females (Stage 0) and recovering ovaries in adult females at the start of the reproductive cycle (Stage 1a). Stage 0 ovaries were so thin and translucent that they were hardly visible during dissection (Figure 2). Stage 1a ovaries were also thin and thread-like, but their color ranged from opaque white to cream (Table 1; Figures 2 and 4).

Stages 2-4 ovaries showed darkening shades of green and represent progressive stages of ovary maturation accompanied by the accumulation of green yolk (Figures 2 and 4). The whole ovary increased enormously in size during the transition from Stages 2 to 4 . Pale green ovaries in different shades were assigned to Stage 2, larger, bright green ovaries which started to extend into the pleon were classified as Stage 3 and dark green, very swollen ovaries that extended into the second pleomer or further posteriorly were assigned to Stage 4 (Table 1; Figures 2 and 4).

Resorbing ovaries, which have a mottled appearance, were divided into two stages: spent ovaries with partial resorption of oocytes that remain in the ovary after spawning (Stage 5a; Figures 1, 2,5) and ovaries that undergo full resorption in females which did not spawn (Stage $5 \mathrm{~b}$; Figures 1-3, and 5). Figure 3 shows the progression of ovary resorption in Stage $5 \mathrm{~b}$ from green ovaries with few yellow spots to yellow ovaries with few green spots. After all the green yolk was resorbed, the ovary appeared bright yellow (Stage 1b; Figures 1-3, and 5).

The typical pattern of the ovarian cycle runs through Stages 1a, 2, 3, 4, 5a and back to Stage 1a (Figure 1). However, maturation can be interrupted during the development from Stages 2 to 3 and to Stage 4. When maturation is arrested, females then resorb their ovaries, first entering 
Stage $5 \mathrm{~b}$ and then the oocytes are resorbed until the green yolk has disappeared in Stage $1 \mathrm{~b}$. After the full resorption is completed, the "normal" cycle is resumed by entering ovary maturation in Stage 1a or 2 (Figure 1).

\subsection{Microscopic observations}

The ovarian lobes were enclosed by the ovarian envelope consisting of connective tissue and an inner layer of epithelium. The germinative zones run centrally through the ovarian lobes, while the maturation zones lie at the outside. The oocytes develop during their transport to the maturation zones where the most developed types of oocytes are found. A convoluted epithelium stretched through the ovary, surrounded the germinative zones and formed several pouches and follicles. Here, we present detailed descriptions of the cellular development of oocytes within the ovary, to characterize and validate the macroscopic observations used for the proposed staging scale. Descriptions here refer to tissue stained with Masson-Goldner trichrome, which allows visualization of more cytological detail than traditional haematoxylin and eosin (HE) staining. However, most of the diagnostic histological features are clear in HE or even monochromatic staining.

We classified germ cells in the developing ovaries of $N$. norvegicus into eight different stages based on cell size, location within the ovary, progression of yolk formation (vitellogenesis), appearance of the nucleus, and characteristics of the cytoplasm (Table 2, Figure 6). The immature reproductive cells, oogonia (og), and degenerating or atresic cells in resorbing ovaries (ao) are separate from the main stages of oocyte development. We have grouped oocytes in the main six stages into three different classes: primary pre-vitellogenic oocytes (early, oc1; and late, oc2), oocytes in primary vitellogenesis (early, oc3; intermediate, oc4) and oocytes in secondary vitellogenesis (advanced, oc5; late, oc6).

Initial oogonia are produced mitotically in the germinative zones, located centrally in the ovary lobes (Figure 6a, b). The heterochromatin was irregularly distributed in the oogonia. The cytoplasm was small and hardly visible. The ovary epithelium enclosing the germinative zone and facing the proliferating oogonia had a fringed appearance (Figure 6a). 
Oogonia undergo meiosis and proliferate into primary pre-vitellogenic oocytes (oc1), which had a distinct nucleolus in the nucleus and predominantly smooth cytoplasm (Figure 6a, b). Primary oocytes multiplied in size during the transport toward the maturation zone at the periphery of the ovary, before they entered the primary phase of vitellogenesis. Early (oc1) and late (oc2) primary oocytes mainly differed in size and the appearance of the cytoplasm. The cytoplasm of early primary oocytes (oc1) was very small, smooth, and barely stained (Figure 6a, b). Late primary oocytes (oc2) had well-developed cytoplasm that stained light pink and showed few dark pinkand turquoise-staining, granular inclusions (Figure 6b).

The cytoplasm of early vitellogenic oocytes (oc3) still mainly stained light pink but appeared very granular due to numerous turquoise-staining inclusions and the starting formation of vesicles (which are interpreted as yolk precursors) (Figure 6c). The cytoplasm of oocytes in intermediate vitellogenesis (oc4) was heterogeneous (Figure 6d). A smooth area had developed around the central nucleus, from which turquoise-staining vesicles originated and filled the central part of the oocytes. Unstained vesicles were distributed throughout the cytoplasm and presumably represented lipid droplets. At this stage, the oocytes had reached a size so that they were tightly surrounded by the ovary epithelium that forms the follicles. The epithelial cells, referred to as follicle cells, had oval nuclei arranged horizontally to the oocytes surface (Figure 6d).

Oocytes in advanced vitellogenesis (oc5) are almost mature. Their nuclei stained darker and increasingly red in contrast to the lightly stained nuclei of intermediate vitellogenic oocytes and any earlier oocyte type. From this stage onward, oocytes were so large that the surrounding ovary epithelium appears thin and stretched, and the nuclei of follicle cells were more elongated than in previous stages. Advanced vitellogenic oocytes (oc5) showed turquoise and bright red colors in different proportions (Figure 6e, f) due to the cytoplasm being increasingly filled with red-staining fully developed yolk vesicles. Turquoise staining vesicles still originated from the smooth area surrounding the nucleus (Figure 6f). In late vitellogenic oocytes (oc6), the cytoplasm was completely filled with red-staining yolk vesicles (Figure 6g). They were so densely packed, that the cytoplasm appeared almost homogenous. The area around the nucleus stained red, similar to the remaining cytoplasm. The nuclei were more irregularly shaped than in previous stages and often found close to the oocyte membrane instead centrally in the cytoplasm. 
Ovaries with late vitellogenic oocytes were difficult to section as the yolk was brittle, apparently resistant to wax infiltration, and detached from the slides easily.

Finally, we differentiate an additional stage: atresic oocytes (ao) under resorption (Figure 6h). Their degeneration became apparent through the irregular shape and corrugated surface. Resorbing oocytes (ao) separated from the surrounding follicle epithelium and showed irregular staining properties throughout the cytoplasm.

\subsection{Correlation of microscopic and macroscopic characters}

Germinative zones within the ovary were active in all stages. Oogonia, primary oocytes (oc1, oc2) and early vitellogenic oocytes (oc3) were always present, even before the female reached sexual maturity (Stage 0; Figure 7). The different stages of maturation in the female were represented by the stage of the most-developed oocytes within the ovary. The overall organization and the proportion of different germ cell types in the ovary also showed distinct characteristics between stages. Properties and density of microscopic vitellogenic development in turn affected the visible macroscopic color.

The immature ovary of juvenile females (Stage 0) was small and dominated by primary oocytes (oc1, oc2) with few early vitellogenic oocytes (oc3), which stained violet (Figure 7). The earliest stage in adult females, the recovering ovary (Stage 1a) was different, with degeneration of empty follicles and clear signs of primary vitellogenesis as early (oc3) and intermediate vitellogenic oocytes (oc4) started to fill the maturation zones (Figure 8a). Stage 2 ovaries were entering secondary vitellogenesis and showed a mix of intermediate (oc4) and advanced vitellogenic oocytes (oc5) in the maturation zones (Figure 8b). The maturation zones in Stages 3 and 4 appeared much larger compared to the germinative zone in previous stages (Figure 8c, d). Stage 3 ovaries still showed intermediate (oc4) and advanced vitellogenic oocytes (oc5) but vitellogenesis was more progressed than in Stage 2 and this was visible by the larger proportion

of red-staining yolk vesicles (Figure 8c). Stage 4 ovaries were filled with advanced (oc5) and late vitellogenic oocytes (oc6). Almost the whole ovary appeared bright red in stained sections, as it was filled with red yolk, giving the bright green appearance in macroscopic observations. The germinative zones occupied only a small space, centrally in the ovary, and early and intermediate oocytes (oc3, oc4) were absent (Figure 8d). Spent Stage 5a ovaries were collapsed and showed 
many empty follicles from where the fully developed oocytes had been ovulated at spawning (Figure 9a, c, d). The germinative zones were highly active and many primary oocytes were present (Figure 9b). Some oocytes had already entered primary vitellogenesis (oc3) in anticipation of the next cycle (Figure 9a). A few atresic (ao), almost fully degenerated oocytes were observed (Figure 9b). In some cases, early primary oocytes (oc1) appeared to develop within fluid remains of atresic oocytes (ao) (Figure 9). The tissue structure of the ovarian envelope was most clearly observed in the spent ovary as it was not stretched as in later stages of maturation (Figure 9d).

The fully resorbing ovary, which appeared mottled in macroscopic observations, microscopically showed a regression from a domination of secondary back to primary vitellogenic oocytes. The overall appearance was disorderly, with primary oocytes found in the maturation zones while advanced vitellogenic oocytes were present centrally in the ovary, close to the highly active germinative zones (Figure 10a, b). The cytoplasm of vitellogenic oocytes was irregularly stained and many atresic oocytes (ao) were observed (Figure 10b, c). Vesicles, different from the ones in maturing ovaries, were observed in some atresic oocytes (Figure 10d). The follicle epithelium surrounding atresic oocytes could stain bright red, which may represent the re-uptake of yolk from the degenerating oocytes (Figure 10d). Figure 11 shows a Stage 1b ovary, which had a yellow appearance in macroscopic view, where resorption was almost completed. A few atresic oocytes (ao) were still observed but the red-staining yolk (i.e., the yolk that appears green in macroscopic view) was no longer present. Most oocytes in the maturation zones resembled intermediate vitellogenic oocytes. They had a turquoise-staining cytoplasm, which appeared more irregular than that of equivalent intermediate vitellogenic oocytes (oc4) in maturing ovaries. The germinative zones of the ovary were highly active and the central ovary was dominated by primary oocytes and early vitellogenic oocytes. Many primary oocytes developed within pink fluid remains of oocyte resorption (Figure 11b).

\section{DISCUSSION}

\subsection{The importance of staging standards}

Despite its economic importance, and the great efforts undertaken to improve stock assessment of $N$. norvegicus in fished populations (FU), this study is the first to incorporate macroscopic observations and microscopic techniques to develop a comprehensive, standardized staging 
scale. Many studies on the ovary maturation of $N$. norvegicus in the previous literature use either one approach or the other (Supporting Information Table S1), or the utility is limited by image quality of published histological sections (de Figueiredo, 1972; Farmer, 1974). In the most recent microscopic descriptive study (Rotllant et al., 2005), macroscopic observations were too brief to be implemented as a staging scale.

Underwater camera (UWC) surveys of burrow densities are the current main tool for stock assessment of $N$. norvegicus. However, many important parameters cannot be assessed through such UWC surveys. Major institutions still conduct regular trawl surveys to collect information on size distributions, sex ratios, and reproductive parameters, including the maturation stages of females. During the course of this study, we found that different staging scales for data collection are still in use across Europe, despite efforts by the International Council of the Exploration of the Sea (ICES) to unify and standardize a staging scale for N. norvegicus (ICES, 2004, 2009). These inconsistencies hamper any efforts to compare long-term data sets within and across different FUs. The aim of this study was to provide a better tool to accurately and consistently assess $N$. norvegicus populations in the future. With an increasing demand for shellfish, a high intensity of exploitation and a rapidly changing environment, this valuable species might be under threat and a sustainable management relies on a prompt detection of potential shifts in the composition of populations. A well-informed standard in data collection is therefore requisite for stock assessment and evidence-based fisheries management.

\subsection{Introducing color standards to staging scales}

The staging color charts (Figures 4, 5) show the approximate range of colors in the ovaries for each stage, except for the Stage 0 ovary which is translucent white. The mottled resorbing ovaries (Stages 5a and 5b) are bi-colored and show a mix of the light/yellow and green shades (Figure 5). The charts are based on the recorded color codes for ovaries (Supporting Information Table S2), the photographs of specimens together with the RAL color charts (examples in Figure 3) under consideration of the microscopically observed stage of ovarian development. The most frequently recorded colors were chosen for the charts herein. Therefore, additional colors may occur in some ovaries. As ovary maturation is a continuous process and not only color but also size and texture are important factors when staging, a certain overlap can occur in 
the color range between adjacent stages. The order of colors (Figures 4 and 5) does not necessarily represent the succession of colors appearing in the ovary during maturation, but the variety of colors observed in each stage.

Color descriptions and images of stages lack standardization, not only in the most recent report of the ICES workshop addressing the scaling issue (ICES, 2009) but also in virtually all staging scales published to date (Supporting Information Table S1). While experienced observers can certainly differentiate the main stages, a universal standard ensures that all users apply the same boundaries to classify intermediate cases. Ovary maturation is a continuous process so the separation of discrete stages is somewhat artificial and challenging, especially to less experienced recorders. The only prior scale that used color standards to describe ovaries in different maturation stages of $N$. norvegicus was Thomas (1964) using Ridgway's color standards and nomenclature (Ridgway, 1912). In all other studies, colors are described in prose. Such color descriptions are rather subjective and, may shift with historic changes, or represent a local rather than a universal understanding of color.

The use of international standards to quantify color has been used in many other contexts in food science (Costa et al., 2013) and ecology (Gerald, Bernstein, Hinkson, \& Fosbury, 2001). The only available study that uses standardized Pantone colors to assess ovary maturation is by Comeau and Savoie (2002) and deals with female H. americanus. However, color codes recorded in this study have not been used to develop a staging scale. Standards based on RGB values or color matching systems (Pantone, RAL) ensure replicability. Use of the RAL color chart photographed within the specimen image was important in this context. Similar ovary colors turned out different across the many photographs we took in different lighting environments; however, the matching color chart next to the specimen allowed for rapid color calibration. An ongoing study on the economically important snow crab, Chionoecetes opilio, in Canada is currently testing the use of a spectrophotometer to assess color in the development of ovaries, eggs, and carapace condition (M, Moriyasu, personal communication, June 10, 2017). This direct quantification of color would probably provide the most accurate assessment. Colors from other universal standards, such as the RAL codes documented here, can easily be compared to spectrophotometric results and standard color charts remain a more inexpensive and less technically complex approach. 


\subsection{The proposed versus previous staging scales and practical recommendations}

Based on combined evidence from microscopic and macroscopic observations, including color codes, we recognized a total of eight distinct stages of ovary maturation in N. norvegicus. To be as consistent as possible with earlier scales (Supporting Information Table S1), we sustained a numbering system from Stages 0 to 5 . Additional splits, where there are two biologically distinct stages, are indicated through letters $(\mathrm{a}, \mathrm{b})$. These distinguish the different reproductive pathways (5a, 1a, 5b, 1b; see Figure 1).

Undeveloped, immature ovaries in juvenile females (Stage 0 in this study) have not typically been distinguished from the earliest recovering stage of adult females (Stage 1a in this study) (Farmer, 1974; Powell \& Eriksson, 2013). However, accurate recognition of immature animals is very important for maturity studies. If adult females are included as immature individuals into calculations of maturity studies, the resulting SOM may artificially inflate. We have shown that immature ovaries of juvenile females can be easily distinguished from recovering ovaries of adult females through macroscopic observations. The immature Stage 0 ovary of juveniles is either not visible to the naked eye or barely visible in the form of very thin, translucent white threads. In contrast to this, the recovering (Stage 1a) ovary of adult females is opaque white to cream. As pointed out by Rotllant et al. (2005), this stage is not a resting stage as germinative zones are active. We refer to it as "recovering" due to the observed partial resorption evident through few atresic oocytes, and the presence of empty follicles that are under regression.

Based on macroscopic observations, the opaque white and cream-colored early maturing ovaries (combined in Stage 1a in this study) could be split into two separate stages as proposed by Symonds (1972); however, as great differences in terms of ovary size and histology were not observed, we refrained from further dividing Stage 1a, to keep the number of stages to a minimum.

Previous staging schemes differ in the number of stages for maturing ovaries in various shades of green (Stages 2-4 in this study; Supporting Information Table S1). According to our study, Stages 2-4 can be easily distinguished through macroscopic and microscopic characteristics; while a distinction is not obligatory, it may have implications for maturity studies as females above Stage 2 are often considered mature when calculating SOMs (e.g., McQuaid, Briggs, \& 
Roberts, 2006). Other studies consider Stage 2 ovaries mature as vitellogenesis is evident (Tuck, Atkinson, \& Chapman, 2000). However, the estimation of SOM also depends on the season in which females are studied (Tuck et al., 2000). For example, in summer samples, Stage 2 females likely include individuals that mature for the first time, but these are not going to spawn until they complete another molt and increase in size. In this context, a differentiation between early (Stage 2), advanced (Stage 3), and mature ovaries (Stage 4) seems important.

We recommend to not treat berried females as a "stage" within the ovary maturation scale as in some previous staging scales (e.g., ICES, 2004; Supporting Information Table S1). The ovary is an internal structure that has a separate developmental phase from the fertilized ova that are brooded externally. The incubation of embryos can take 4-5 months in the Mediterranean (Relini, Zamboni, Fiorentino, \& Massi, 1998) to 12-13 months in Icelandic waters (Eiríksson, 2014). Information for the Irish Sea ranges from 8 to 9 months (Farmer, 1974; Powell \& Eriksson, 2013). While embryos develop during these long times, the ovarian cycle is resumed and, thus, different ovary stages are represented in berried females. We therefore recommend to first separate berried females from females without eggs and record an ovarian stage afterward, so that both presence or absence of eggs and the state of the ovary are recorded.

In the resorbing stages, a clear distinction between partial (Stage 5a) and full ovary resorption (Stage $5 \mathrm{~b}$ ) is done. Stage 5a ovaries undergo partial resorption of a few remaining oocytes, which have not been extruded. Ovaries in Stage 5a are spent and females are therefore always ovigerous, while female with Stage $5 \mathrm{~b}$ females never carry eggs. In the latter case, ovaries in advanced maturation stages undergo full resorption as females have not spawned but instead recycle nutrients by resorbing vitellogenic oocytes (Bailey, 1984). The staging scale currently recommended for surveys across Europe recognises partial resorption in spent ovaries as a separate stage but states that full resorption can occur in any maturation stages with signs of yolk accumulation (Stage 3-5 in ICES, 2009). We propose an additional stage (1b) for females with bright yellow ovaries which have completed full resorption and are likely to be re-entering a regular reproductive cycle.

The process of ovary resorption has been microscopically described in detail for the first time in this study. We consider the distinction between partial resorption in spent ovaries (Stage 5a) and 
full resorption in females that failed to spawn (Stage 5b, 1b) essential for an accurate assessment of stocks. While partial resorption after spawning is a regular and natural phenomenon in the reproductive cycle, the full resorption instead of spawning can be regarded as an interruption of the annual cycle as affected females skip one reproductive season (Bailey, 1984). A high incidence of resorption might therefore lead to a reduced reproductive capacity of stocks and may serve as an indicator for the vulnerability to exploitation in affected populations.

The phenomenon of full ovary resorption in the female reproductive cycle should also be taken into consideration when biennial reproductive cycles are assumed for some populations of $N$. norvegicus (e.g., Eiríksson, 1993; Symonds, 1972). In Icelandic N. norvegicus, the incubation of eggs is supposed to take longer than a year (12-13 months), indicating a biennial cycle (Eiríksson, 1993). Whether ovary maturation is likewise prolonged in this population remains unknown. Ovary maturation stages observed in Icelandic waters are similar to the ones described in this study; however, the seasonal occurrence of stages is different from populations in U.K. waters. Low percentages of females (0-4\%) showed signs of resorption in Icelandic populations in Spring (May) (Eiríksson, 2014). To understand whether the phenomenon of ovary resorption may be responsible for the assumption that the reproductive cycle is biennial in Icelandic $N$. norvegicus, summer samples should be studied in future surveys.

\subsection{Significance of microscopic observations}

The terminology and definitions for developing germ cells vary considerably in the literature (e.g., Braga, Nunes, López-Greco, Camargo-Mathias, \& Fransozo, 2016; CharniauxCotton, 1975; Desantis et al., 2001; ICES, 2009). Several studies have investigated oogenesis through ultrastructural features of oogonia and oocytes using electron microscopy (e.g., Charniaux-Cotton, 1985; Hinsch \& Cone, 1969). Electron microscopy studies are, however, not easily translated into light microscopic studies as cell organelles and other cellular details are not visible in histological sections. Especially the distinction between oogonia and early primary oocytes is difficult without transmission electron microscopy.

Our terminology and distinction between germ cells is based on the microscopic germ cell scale proposed by ICES (2009), with some adaptations and changes based on our histological results specific to $N$ norvegicus. The ICES report on crustacean maturity stages used the same 
microscopic scale for all species outlined in that report. Microscopic reference images were presented for several shrimp species, but unfortunately not for $N$. norvegicus (ICES, 2009). In contrast to the germ cell descriptions in ICES (2009), in N. norvegicus we did not observe differences in the number, appearance or location of nucleoli within nuclei among the different oocyte stages, only the nucleoli of oogonia were not as round and well-defined as the nucleoli of oocytes and also stained slightly darker.

The accumulation of yolk in developing oocytes occurs in two steps, the primary and secondary vitellogenesis (Bailey, 1984). Smith (1987) considers all stages up to fully mature oocytes as primary vitellogenesis, while secondary vitellogenesis is supposed to only occur in females close to spawning, yet we observed significant changes in yolk vesicles in the cytoplasm earlier than that (Table 1). However, only ultrastructural and biochemical studies can elucidate the process of vitellogenesis in detail.

There is some controversy about the source of yolk within crustacean eggs, and whether vitellogenesis is solely promoted by intra-ovarian yolk production or whether it might be supplemented through extraovarian nutrients (Fainzilber, Tom, Shafir, Applebaum, \& Lubzens, 1992; Tsukimura, 2001). We found that the area around the nucleus (the endoplasmatic reticulum) was highly active in intermediate and advanced vitellogenic oocytes (oc4, oc5), which represents the intracellular component of yolk production. Other studies on the chemical composition of ovaries, the hepatopancreas and other tissues in $N$. norvegicusduring ovary maturation found that lipid, protein, and water content increased during maturation, while the carbohydrate content decreased (Rosa \& Nunes, 2002; Tuck et al., 1997). A decrease in the lipid content of the hepatopancreas was not balanced with any increase of the lipid content in the ovary during maturation, which would have indicated a transfer of nutrients from the hepatopancreas to the ovary during maturation. Tuck et al. (1997), however, pointed out that such a transfer could be immediately compensated in the hepatopancreas by food uptake. In female $N$. norvegicus with resorbing ovaries, there is apparently a reverse transfer of nutrients from the ovary to surrounding tissues and/or hemolymph. The hemolymph of resorbing females turns green due to the re-uptake of nutrients from ovaries. In our study, this was most obvious in Stage $1 \mathrm{~b}$ females with fully resorbed ovaries (Figure 2; Stage $1 \mathrm{~b}$ ). 


\subsection{Conclusions and application of the new unified staging scale}

The new scale presented here distinguishes two separate pathways to the reproductive cycle, which were not clear in previous, linear staging scales. Resorbing ovaries may represent a natural end to resorb the last few oocytes after successful reproduction (Stage 5a) or they may be an abortive stage where the animal does not breed at all in that cycle (Stage 5b). While the appearance is similar, the significance of a large proportion of resorbing ovaries in a population is quite different depending on which pathway is represented (Figure 1).

When staging is conducted on board of fisheries vessels, landing live specimens instead of processing (tailing) them on board, a dissection of the ovary may not be possible. Thus, there is a need to stage females alive. A high resolution staging method is then not applicable. The posterior ovarian lobes can, however, be observed through the gap between the posterior carapace margin and the pleon (tail) when bending females carefully. The discrimination between immature and undeveloped ovaries that appear very pale (Stages 0 and 1a) versus maturing ovaries that show shades of green (Stages 2-4), should still be possible. More detailed differentiation between juvenile females (Stage 0) and the recovering ovaries in adult females (1a) is impossible, and stages showing signs of resorption (Stage 1b, 5a, and 5b) might be overlooked.

For practical application, we present an alternative, simplified scale, which can be used if rapid processing of large sample batches is required, for example in shipboard surveys (Table 3). The proposed simplification of stages has a lower resolution, yet still allows a distinction between ovaries of juvenile and adult females, which is crucial for SOM studies.

Changing standards can pose a problem to the continuity and transferability of data collected in long-term surveys. While some stages can be easily converted into one another, stages that were not previously recognized or understood cannot be applied retrospectively. It is crucial that identified stages are biologically relevant, and that the macroscopic changes are accurately crossvalidated with microscopic phases of oocyte development. It is our hope that this study represents a comprehensive and sufficiently detailed examination of the female reproductive cycle in $N$. norvegicus, that it will clarify the distinction between relevant stages in maturity and 
development and provide practical tools for gathering future long-term data sets with enhanced value for biology and fisheries management.

\section{Acknowledgements}

This project was funded by the UK Sea Fish Industry Authority's (Seafish) Strategic Investment Programme 2015-18. Co-funding was received from Kilkeel/Whitby Seafoods (UK). We thank Lynn Gilmore, William Lart, Phil McMullan (Seafish), and Daniel Whittle (Kilkeel/Whitby Seafoods) for their support of this project. We would also like to thank the Agri-Food and Biosciences Institute (AFBI) for their support and for giving us the opportunity to take part in their 2016 trawl survey to collect samples. We especially thank Peter McCorriston and Mathieu Lundy (AFBI) as well as the crew of RV Corystes. We also thank the ICES working group on Nephrops (WGNEPS) for the invitation to a meeting in Heraklion/Crete (November 28, 2017/December 1, 2017) and fruitful discussions on staging scales. We thank Emma Gorman (Queen's University Belfast, UK) for giving her help with sample processing and Jutta Zeller (Museum für Naturkunde, Berlin, Germany) for her help with tissue infiltrations and embedding). A special thank goes to graphic designer Holger Klein (Frankfurt, Germany) who has kindly prepared the illustration on the ovary maturation cycle (Figure 1).

\section{References}

Aiken, D. E., \& Waddy, S. L. (1980). Reproductive biology. In J. S. Cobb \& B. F. Phillips (Eds.), The biology and management of lobsters, Vol. 1: Physiology and behaviour (1st ed., pp. 215-276). New York, NY: Academic Press.

Bailey, N. (1984). Some aspects of reproduction in Nephrops. International Council of the Exploration of the Sea, Shellfish Committee Document, CM 1984/K:33, pp. 1-15.

Braga, A. A., Nunes, E. T., López-Grecco, L. S., Camargo-Mathias, M. I., \& Fransozo, V. (2016). Histological and histochemical features of the oogenesis in the simultaneous protandric hermaphrodite shrimp Exhippolysmata oplophoroides (Decapoda: Caridea). Micron, 88, 60-67. 
Briggs, R. P. (1988). A preliminary analysis of maturity data for northwest Irish Sea Nephrops. International Council of the Exploration of the Sea, Shellfish Committee Document, CM 1988/K:16, pp. 1-16.

Charniaux-Cotton, H. (1975). L'ovogenèse et sa régulation chez les crustacés supérieurs. Annales de Biolgie Animale, Biochimie, Biophysique, 15, 715-724.

Charniaux-Cotton, H. (1985). Vitellogenesis and its control in malacostracan Crustacea. American Zoologist, 25, 197-206.

Comeau, M., \& Savoie, F. (2002). Maturity and reproductive cycle of the female American lobster, Homarus amercianus, in the southern gulf of St. Lawrence, Canada. Journal of Crustacean Biology, 22, 762-774.

Costa, C., Antonucci, F., Menesatti, P., Pallottino, F., Boglione, C., \& Cataudella, S. (2013). An advanced colour calibration method for fish freshness assessment: A comparison between standard and passive refrigeration modalities. Food and Bioprocess Technology, 6, 2190-2195.

de Figueiredo, M. J. (1972). Alguns aspectos da histologia do ovário do lagostim (Nephrops norvegicus) e do camarão (Penaeus kerathurus) durante o seu ciclo maturativo. Boletim Informativo do Instituto Bioolgia Marítima, 7, 1-20.

de Figueiredo, M. J. (1982). The occurence of resorbtion in the ovaries Nephrops norvegicus (L.) in Portuguese waters. International Council of the Exploration of the Sea, Shellfish Committee Document, CM 1982/K:28, pp. 1-7.

de Figueiredo, M. J., \& Barraca, I. F. (1963). Contribuição para o conhecimento da pesca e da biologia do lagostim (Nephrops norvegicus L.) na costa portuguesa. Notas e Estudos do Instituto Bioolgia Marítima, 28, 1-44.

de Figueiredo, M. J., \& Thomas, H. J. (1967). On the biology of the Norway lobster, Nephrops norvegicus (L.). ICES Journal of Marine Sciences, 31, 89-101. 
Desantis, S., Labate, M., Maiorano, P., Tursi, A., Labate, G. M., \& Ciccarelli, M. (2001). A histochemical and ultrastructural study of oogenesis in Aristaeomorpha foliacea (Risso, 1827). Hydrobiologia, 449, 253-259.

Eiríksson, H. (1993). On the biennial breeding cycle of Nephrops at Iceland and how it relates to the fishery. International Council of the Exploration of the Sea, Shellfish Committee Document, CM 1993/K:5, pp. 1-18.

Eiríksson, H. (2014). Reproductive biology of female Norway lobster, Nephrops norvegicus (Linnaeus, 1758) leach, in Icelandic waters during the period 1960-2010. Comparative overview of distribution areas in the Northeast Atlantic and the Mediterranean. In M. Lesser (Ed.), Advances in marine biology (pp. 65-210). Oxford: Elsevier.

Fainzilber, M., Tom, M., Shafir, S., Applebaum, S. W., \& Lubzens, E. (1992). Is there extraovarian synthesis of vitellogenin in penaeid shrimp? Biological Bulletin, 183, 233-241.

Farmer, A. S. D. (1974). Reproduction in Nephrops norvegicus (Decapoda:

Nephropidae). Journal of Zoology, 174, 161-183.

Gerald, M. S., Bernstein, J., Hinkson, R., \& Fosbury, R. A. (2001). Formal method for objective assessment of primate color. American Journal of Primatology, 53, 79-85.

Hinsch, G. W., \& Cone, M. V. (1969). Ultrastructural observations of vitellogenesis in the spider crab, Libinia emarginata L. Journal of Cell Biology, 40, 336-342.

ICES (2004). Report of the 2004 I.E. Working Group on Nephrops stocks (WGNEPH Report), pp. $1-435$.

ICES (2009). Report of the workshop on crustaceans (Aristeus antennatus, Aristaeomorpha foliacea, Parapenaeus longirostris, Nephrops norvegicus) maturity stages (WKMSC), 19October 23, 2009, Messina, Italy; International Council of the Exploration of the Sea, Shellfish Committee Document, CM 2009/ACOM:46, 1-75. 
MacDiarmid, A. B., \& Sainte-Marie, B. (2006). Reproduction. In B. F. Phillips (Ed.), Lobsters: Biology, management, aquaculture and fisheries (pp. 45-77). Oxford: Blackwell Publishing Ltd.

McQuaid, N., Briggs, R. P., \& Roberts, D. (2006). Estimation of the size of onset of sexual maturity in Nephrops norvegicus (L.). Fisheries Research, 81, 26-36.

Powell, A., \& Eriksson, S. P. (2013). Reproduction: Life cycle, larvae and larviculture. In M. L. Johnson \& M. P. Johnson (Eds.), Advances in marine biology. The ecology and biology of Nephrops norvegicus (pp. 201-245). London: Elsevier.

Relini, L. O., Zamboni, A., Fiorentino, F., \& Massi, D. (1998). Reproductive patterns in Norway lobster Nephrops norvegicus (L.), (Crustacea Decapoda Nephropidae) of different Mediterranean areas. Scientia Marina, 62, 25-41.

Ridgway, R. (1912). Color standards and color nomenclature. Washington DC.

Rosa, R., \& Nunes, M. L. (2002). Biochemical changes during the reproductive cycle of the deep-sea decapod Nephrops norvegicus on the south coast of Portugal. Marine Biology, 141, 1001-1009.

Rotllant, G., Ribes, E., Company, J. B., \& Durfort, M. (2005). The ovarian maturation cycle of the Norway lobster Nephrops norvegicus (Linnaeus, 1758) (Crustacea, Decapoda) from the western Mediterranean Sea. Invertebrate Reproduction and Development, 48, 161-169.

Seafish, 2018. Seafish Industry Factsheet, pp. 1-15. Accessed online May 15, 2018 at http://www.seafish.org/publications

Smith, R. S. M. (1987). The biology of larval and juvenile Nephrops norvegicus (L.) in the Firth of Clyde. Dissertation, Glasgow University.

Symonds, D. J. (1972). The fishery for the Norway lobster, Nephrops norvegicus (L.) off the north-east coast of England. Fishery Investigations, 27, 1-35. 
Talbot, P., \& Helluy, S. (1995). Chapter 9 - Reproduction and embryonic development. In J. R. Factor (Ed.), Biology of the lobster (pp. 177-216). Cambridge: Academic Press.

Thomas, H. J. (1964). The spawning and fecundity of the Norway lobsters (Nephrops norvegicus L.) around the Scottish coast. ICES Journal of Marine Sciences, 29, 221-229.

Tsukimura, B. (2001). Crustacean vitellogenesis: its role in oocyte development. American Zoologist, 41, 465-476.

Tuck, I., Atkinson, R. J. A., \& Chapman, C. J. (2000). Population biology of the Norway lobster, Nephrops norvegicus (L.) in the firth of Clyde, Scotland II: Fecundity and size at onset of sexual maturity. ICES Journal of Marine Sciences, 57, 1227-1239.

Tuck, I. D., Taylor, A. C., Atkinson, R. J. A., Gramitto, M. E., \& Smith, C. (1997). Biochemical composition of Nephrops norvegicus: Changes associated with ovary maturation. Marine Biology, 129, 505-511.

Ungfors, A., Bell, E., Johnson, M. L., Cowing, D., Dobson, N. C., Bublitz, R., \& Sandell, J. (2013). Nephrops fisheries in European waters. In M. L. Johnson \& M. P. Johnson (Eds.), Advances in marine biology. The ecology and biology of Nephrops norvegicus (pp. 247314). London: Elsevier. 